\title{
Indications and rate of caesarean delivery at tertiary care hospital: a retrospective study
}

\author{
Reena Sharma*, Poojan Dogra
}

Department of Obstetrics and Gynecology, SLBS GMC Mandi at Nerchowk, Himachal Pradesh, India

Received: 08 July 2017

Revised: 05 August 2017

Accepted: 18 August 2017

\section{*Correspondence:}

Dr. Reena Sharma,

E-mail: dreenajay@gmail.com

Copyright: () the author(s), publisher and licensee Medip Academy. This is an open-access article distributed under the terms of the Creative Commons Attribution Non-Commercial License, which permits unrestricted non-commercial use, distribution, and reproduction in any medium, provided the original work is properly cited.

\begin{abstract}
Background: Worldwide there has been an increase in the rate of caesarean delivery due to multiple factors. Objective of the study was to assess the prevalence and different indications of caesarean section in this institute.

Methods: The aim of the study is to analyse the rates and indications of lower segment caesarean section (LSCS) in our institution. We conducted a retrospective study over a period of six months; $1^{\text {st }}$ September 2016 to $1^{\text {st }}$ March 2017 at SLBSGMC Mandi at Nerchowk. Total number of patients who delivered in our hospital during the defined study period was recorded and a statistical analysis of various parameters was done.

Results: The total number of women delivered over the study period was 2075, out of which caesarean sections (CS) were 473 . The overall CS rate calculated was $22.8 \%$. Previous LSCS was the leading indication to the CS rate.

Conclusions: Routine obstetric audits should be done to analyse the various indications of emergency and elective caesarean sections so that protocols and guidelines can be implemented to curtail the increasing trend of caesarean delivery.
\end{abstract}

Keywords: Caesarean section, Indications of CS, Previous LSCS

\section{INTRODUCTION}

Caesarean section is a surgical procedure in which one or more incisions are made through abdomen and uterus of the pregnant mother to deliver one or more babies, or to remove a dead fetus. The first modern caesarean section was performed by German gynaecologist Ferdinand Adolf Kehrer in 1881. ${ }^{1}$

Caesarean section is one of the commonly performed surgical procedures in obstetrics and is certainly one of the oldest operations but the most dramatic feature of modern obstetrics is the increase in the caesarean section rate. ${ }^{2,3}$ Caesarean section is common surgical operation with estimated prevalence rate of $33 \%$; prevalence ranges from $4 \%$ in Africa to $29 \%$ in Latin America and Caribbean. ${ }^{4}$
Increasing caesarean section rate is an issue of public health concern globally for last 30 years; its use has increased since 1970 to a level that is medically unjustified. Thus bringing negative, economic and health related repercussion. ${ }^{5} \mathrm{~A}$ rising trend of caesarean sections has been noted with the advent of electronic fetal monitoring, better operative techniques and availability of tertiary care neonatal facilities. When medically justified, a caesarean section (CS) can effectively prevent maternal and perinatal mortality and morbidity. ${ }^{6}$

In recent years, governments and clinicians have expressed concern about the rise in the numbers of caesarean section births and the potential negative consequences on maternal and infant health. High caesarean rates are an issue of international public health concern. ${ }^{7,8}$ 
The objective of this study was to analyse the rates and trends of LSCS in our institution in modern day obstetrics.

\section{METHODS}

The present study was carried out retrospectively over a period of six months- from $1^{\text {st }}$ September 2016 to $1^{\text {st }}$ March 2017 in the Department of Obstetrics and Gynaecology, SLBSGMC Mandi at Nerchowk; a tertiary care institute which cares for over 4000 institutional deliveries per year. The objective of the study was to analyse the trend and indication of LSCS in our institute to frame the appropriate policies to defer the rising trend of LSCS as much as possible.

As this was a retrospective study so after gaining permission from institutional ethical committee we retrieved the record from Department of Obstetrics and Gynecology from labour room, department of Anaesthesia, emergency and elective caesarean section record from operation theatre from $1^{\text {st }}$ September 2016 to $1^{\text {st }}$ March 2017. During above said study period a total of 2075 patients delivered including caesarean section in the institute.

Data was recorded, master chart framed and a statistical analysis of various parameters- age, parity, period of gestation, contraceptive method adopted, elective versus emergency caesarean section and indications for caesarean section in primigravida/multigravida/overall, was done to find out the rate and trend of caesarean section in our institute.

\section{RESULTS}

The total numbers of women delivered over the study period were 2075, out of which CS deliveries were 473 . Overall, caesarean rate calculated for our institution was $22.8 \%$.

Table 1: Distribution of patients who underwent LSCS by age.

\begin{tabular}{|lll|}
\hline Age (Years) & No. of cases & $\%$ \\
\hline$<20$ & 52 & 11.0 \\
\hline $21-25$ & 223 & 47.1 \\
\hline $26-30$ & 144 & 30.4 \\
\hline $31-35$ & 42 & 8.9 \\
\hline $36-40$ & 10 & 2.1 \\
\hline $41-45$ & 2 & 0.4 \\
\hline Total & 473 & 100 \\
\hline
\end{tabular}

Maximum no. of caesarean sections - 223 of 473 (47.1\%) were in the age group of 21-25 years followed by $30.4 \% \%$ patients in the age group of $26-30$ years.

Only $2.5 \%$ of the cases belonged to the elderly age group of 36-45 years (Table 1).
Maximum no. of caesarean sections was primigravida females: $57.1 \%$ (270/473 cases), while in multiparous group contribution is $41.3 \%$ (Table 2), the contributory factor to the majority group being the previous LSCS as the leading indication to the CS rate.

Table 2: Comparison of indications of LSCS according to parity.

\begin{tabular}{|lll|}
\hline Parity & No. of Cases & $\%$ \\
\hline Primigravida & 270 & 57.1 \\
\hline Multigravida & 196 & 41.3 \\
\hline Grandmultigravida & 7 & 1.4 \\
\hline Total & 473 & 100 \\
\hline
\end{tabular}

Only $1.4 \%$ of grand-multiparous patients undergone LSCS.

Table 3: Percentage of LSCS in relation to period of gestation.

\begin{tabular}{|lll|}
\hline Period of gestation & No. of cases & $\%$ \\
\hline Term $(\geq 37$ weeks $)$ & 451 & 95.3 \\
\hline Preterm $(<37$ weeks $)$ & 22 & 4.7 \\
\hline Total & 473 & 100 \\
\hline
\end{tabular}

Majority $95.3 \%$ (451 of 473) of the study group was term ( $\geq 37$ weeks POG) patients (Table 3 ).

Table 4: Percentage of emergency versus elective LSCS.

\begin{tabular}{|lll|}
\hline Type of LSCS & Number & $\%$ \\
\hline Emergency & 300 & 63.4 \\
\hline Elective & 173 & 36.6 \\
\hline Total & 473 & 100 \\
\hline
\end{tabular}

Majority $63.4 \%(300 / 473)$ of the study group were emergency LSCS (Table 4), as we receive lot of referral from peripheral area.

Previous LSCS was the most common indication of caesarean section in the present study accounting for 104 of all CS cases (22\%). Cephalopelvic disproportion accounted for $15.8 \%$ of cases, Breech presentation for $12.5 \%$ cases Acute Fetal distress accounted for 11.2\%; Failed induction for $9.1 \%$; Non progress of labor $8 \%$; Contracted pelvis $6.5 \%$; and Oligohydramnios/IUGR account for $4.5 \%$; Hypertensive disorders of pregnancy (HDP) - 1.8\%; Transverse Lie and Twin Pregnancy each $1.5 \%$ each of total caesarean sections respectively. Rest in decreasing order were antepartum haemorrhage (APH), $\mathrm{BOH}$, DTA, other malpresentations, genital warts, neglected shoulder presentation, previous myomectomy and complete vaginal septum respectively (Table 5).

Majority of patients $78.9 \%$ (343/473) not adopted for any contraceptive method at the time of LSCS. Permanent method tubectomy adopted by $19.5 \%$ of patients. Least adopted method was $\mathrm{Cu}-\mathrm{T}$ by $1.7 \%$ of the patients. 
Table 5: Indications of LSCS.

\begin{tabular}{|c|c|c|}
\hline Indications & No. of cases & $\%$ \\
\hline Prev. LSCS & 104 & 22.0 \\
\hline Cephalopelvic disproportion & 75 & 15.8 \\
\hline Breech & 59 & 12.5 \\
\hline AFD+MSL & 53 & 11.2 \\
\hline Failed induction & 43 & 9.1 \\
\hline Non-progress of labor & 38 & 8.0 \\
\hline Contracted pelvis & 31 & 6.5 \\
\hline IUGR/poor biophysical profile & 21 & 4.5 \\
\hline $\begin{array}{l}\text { Hypertensive disorders in } \\
\text { Pregnancy (sev PIH, PET) }\end{array}$ & 9 & 1.8 \\
\hline Mulifetal Gestation (Twins) & 7 & 1.5 \\
\hline Transverse Lie & 7 & 1.5 \\
\hline $\begin{array}{l}\text { Antepartum haemorrhage } \\
\text { (placenta praevia, abruptio } \\
\text { placenta) }\end{array}$ & 6 & 1.2 \\
\hline $\mathrm{BOH}$ & 5 & 1.1 \\
\hline Deep transverse arrest & 5 & 1.1 \\
\hline Precious pregnancy & 3 & 0.6 \\
\hline $\begin{array}{l}\text { Other malpresentations (brow, } \\
\text { unstable Lie) }\end{array}$ & 2 & 0.4 \\
\hline Genital warts & 2 & 0.4 \\
\hline Neglected shoulder presentation & 1 & 0.2 \\
\hline Prev. myomectomy & 1 & 0.2 \\
\hline Complete vaginal septum & 1 & 0.2 \\
\hline Total & 473 & 100 \\
\hline
\end{tabular}

Table 6: Contraceptive method adopted during LSCS.

\begin{tabular}{|lll|}
\hline Contraceptive method & Number & $\%$ \\
\hline Tubectomy & 92 & 19.5 \\
\hline $\mathrm{Cu}-\mathrm{T}$ & 8 & 1.7 \\
\hline None & 373 & 78.9 \\
\hline Total & 473 & 100 \\
\hline
\end{tabular}

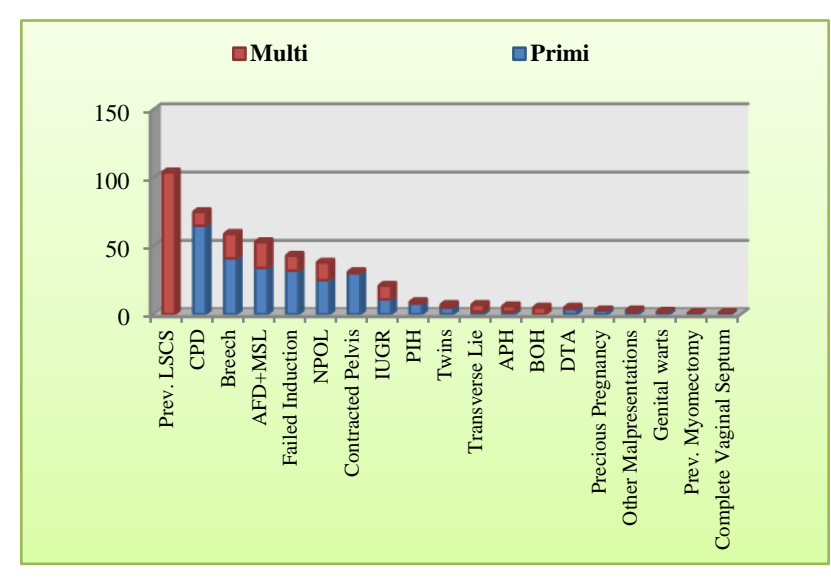

Figure 2: Comparison of indications of LSCS in primigravida and multigravida patients.

\section{DISCUSSION}

The WHO expert panel in its worldwide ecologic study to assess the association between caesarean sections, maternal and neonatal mortality made the following observations

- Increases in CS rates up to $10-15 \%$ at population level are associated with decrease in maternal, neonatal and infant mortality. Above this level, the rate of caesarean section is no longer associated with reduced mortality

- Below a caesarean section rate of $10 \%$, maternal and neonatal mortality decreased when caesarean rates increased. No effect on mortality rates was observed at CS rate between $10-30 \%$

- Current data is insufficient to assess the link between maternal and newborn mortality and rates of caesarean section above $30 \% .^{9}$

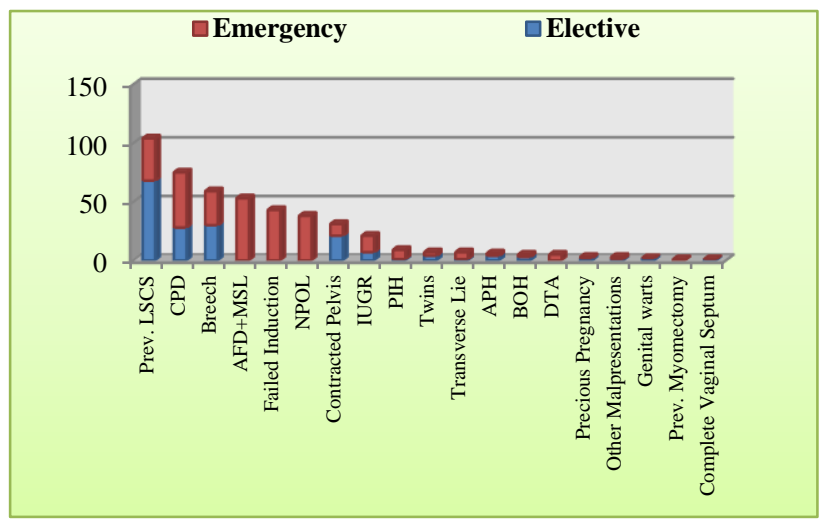

Figure 3: Comparison of indications of emergency and elective LSCS.

Increased rate in developed countries is due to health insurance system, fear of litigation, on demand, extensive use of foetal monitoring. But it is not the rule in our set up as the patients are not given the autonomy of decision making and the health personnel play the key role in patient's decision. Present study revealed a CS rate of (22.8\%) which is comparable to the rates in different centres like Raipur, India (26.2\%), and other South-East Asian Countries like The Philippines (22.7\%), Malaysia (19.1\%), Indonesia (29.6\%). ${ }^{10,11}$ In United Kingdom, the caesarean rate was $24.1 \%$ of all live births. ${ }^{12}$

Caesarean rate observed in our hospital was $22.8 \%$ that is quite high as compared to the accepted upper norm of World Health Organization of $15 \%$, because being a referral hospital, our institute is catering to a large population of referred cases and it has been hypothesized. That one reason of increased CS rate may be due to that procedure being performed at a lower threshold of abnormality detection among the health care providers. ${ }^{13}$

In present study, the most common indication was previous CS $(22.0 \%)$, which is the most the common indication worldwide. Enkin et al analyzed a series of 8899 women who were permitted for trial of labour out of them $20.1 \%$ were delivered by caesarean section and $79.9 \%$ were delivered vaginally. ${ }^{14}$ Almost same results 
were observed by Jawa $\mathrm{A}$ et al and Subedi $\mathrm{S}$ in their study. ${ }^{15,16}$

In present setup trial of labor was not given even after one previous CS until and unless women comes in second stage of labour and this is the cause for increased rate for previous CS and failure to conduct VBAC in our hospital was due to lack of trained human resources. The reluctance to undergo trial of labour after previous CS is probably due to either the obstetrician considering that a repeat $\mathrm{CS}$ is much safer, convenient, there is less chance of complications and possible subsequent litigation or due to maternal preference is the cause of increase rate of repeat CS.

Next indications are cephalopelvic disproportion (CPD$15.8 \%$ ) and contracted pelvis $(6.5 \%)$. There can be several reasons why the pelvis is not suited for birth. Different conditions, including rickettsia, previous pelvic fractures, spondylolisthesis and malnutrition when growing up, may cause malformations of the pelvis. Xray of the pelvis can help decide whether it is suitable as a birth canal, but this is not a common screening procedure. $^{17}$

The pelvis matures and changes during puberty, caesarean section rates increases the younger the mother is, suggesting that pelvic size is an indicator for caesarean delivery. ${ }^{18}$

A baby weighing more than 4500 gram has increased risk of a long lasting birth, shoulder dystocia, injuries of plexus brachialis and clavicle fracture. There is also a risk of vaginal tear, perianal damage and bleeding in the mother. ${ }^{19}$ Symphysis-fundus measurements and ultrasound is used to diagnose a big baby. If the mother had history of birth complications before due to big baby, these cases should be re-evaluated to decide the mode of delivery.

Next indication was Fetal distress $(11.2 \%)$, results are comparable with Jawa A et al (16.06\%). ${ }^{15}$ The gold standard method of estimation of foetal distress is not used in our set up and what we have for foetal monitoring is fetal heart rate monitoring with stethoscope and fetal doppler manually. The accurate method of estimation of foetal distress is foetal scalp $\mathrm{pH}$ estimation. ${ }^{20}$

Caesarean section for Breech was observed (12.5\%) these results are comparable with study done by Subedi S. ${ }^{16}$ Though ECV (external cephalic version) has been suggested as an intervention to reduce high CS rate at 37 wks gestation but it has its own drawbacks and requires skill. A meta-analysis showed significantly lower rates of perinatal mortality and neonatal morbidity with planned caesarean section than with planned vaginal birth. $^{21}$

Caesarean sections for failed induction were $(9.1 \%)$ and NPOL were $(8.0 \%)$ which were comparable with the results of study done by Subedi S. ${ }^{16}$ Judicious use of oxytocic's and the use of partograph are definitely beneficial to reduce the CS rate.

\section{CONCLUSION}

The caesarean section prevalence in our study was $22.8 \%$, as we received lot of referred cases after initial trial of daies, health workers, staff nurses, medical officers from peripheral institutes and general practitioners in private hospitals. Commonest indication of caesarean section observed in this study was previous caesarean section. Measures recommended to reduce the caesarean section rate are as follows:

- Proper antenatal care and counselling regarding the planned hospital delivery.

- Proper diagnosis of labour. Avoiding unindicated inductions of labour.

- Partogram should be maintained for monitoring of progress of labour

- Good analgesia and proper fetal monitoring during labour with CTG and provision of fetal scalp $\mathrm{pH}$ estimation for justified diagnosis of fetal distress.

- Trial of VBAC should be encouraged in appropriate cases.

- Expertise in external cephalic version and vaginal breech delivery in good selected cases.

- Proper training of traditional birth attendants, health workers and medical officers posted in peripheral institutes for justified and timely referral.

- Adequate and appropriate (in term of quantity and quality) infrastructure including trained manpower (staff nurses, doctors) round the clock to work at ground level in labor room to avoid unjustified CS.

\section{Funding: No funding sources \\ Conflict of interest: None declared \\ Ethical approval: Not required}

\section{REFERENCES}

1. Caesarean section. Wikipedia. Available from http://en.wikipedia.org/wiki/Caesarean_section Downloaded 12.02.2013.

2. Turner MJ. Delivery after one previous caesarean section. Am J Obstet Gynecol. 1997;176:741-4.

3. Oladapo OT, Sotunsu JO, Sule-Odu AO. The rise in caesarean birth rate in Sagamu, Nigeria: reflection of changes in obstetrics practice. J Obstet Gynecol. 2004;24:377-81.

4. Betran AP, Mepaldim, Lauer JA, Bingshun W, Thomas J, Vanlook $\mathrm{P}$ et al. Rates of caesarean section: analysis of global, regional and national estimates. Pediatr Perinat Epidemiol. 2007;21:98113.

5. Pádua KS, Osis MJ, Faúndes A, Barbosa AH, Moraes Filho OB. Factors associated with caesarean 
section in Brazilian Hospitals. Rev Saude Publica 2010;44(1):70-9.

6. WHO Statement on caesarean section rates; 2015 , WHO reference number: WHO/RHR/15.02. Available http://www.who.int/reproductivehealth/publications/ maternal_perinatal_health/cs-statement/en/. Accessed on 15 July 2016.

7. Marshall NE, Fu R, Guise JM. Impact of multiple caesarean deliveries on maternal morbidity: a systematic review. Am J Obstet Gynecol. 2011;205(3):262.

8. Lumbiganon P, Laopaiboon M, Gulmezoglu AM, Souza JP, Taneepanichskul S, Ruyan P et al. Method of delivery and pregnancy outcomes in Asia: the WHO global survey on maternal and perinatal health 2007-08. Lancet. 2010;375:490-9.

9. WHO Statement on caesarean section rates; 2015, WHO reference number: WHO/RHR/15.02. available

http://www.who.int/reproductivehealth/publications/ maternal_perinatal_health/cs-statement/en/.

Accessed on 15 July 2016.

10. Singh A, Channawar R. A recent way of evaluating caesarean birth. J Obstet Gynecol India. 2009;59(6):547-51.

11. Festin MR, Laopaiboon M, Pattanittum P, Ewens MR, Henderson-Smart DJ, Crowther CA; SEAORCHID Study Group. Caesarean section in four South East Asian countries: reasons for, rates, associated care practices and health outcomes. BMC Pregnancy Childbirth. 2009 May 9;9:17.

12. WHO Euro Health for all database, 2014. Available at http://data.euro.who.int/hfadb/(53). Accessed on 15 July 2016.

13. Mukherjee SN. Rising caesarean rate. J Obstet Gynecol India. 2006;56(4):298-300.
14. Enkin M. Labour and delivery following previous caesarean section. In Enkin M, Keirs MJ,Chalmers I(eds). Elective Care in Pregnancy and Childbirth, Oxford: Oxford University Press;1989:1196-1215.

15. Jawa A, Garg S, Tater A, Sharma U. Indications and rates of lower segment caesarean section at tertiary care hospital - an analytical study. Int J Reprod Contracept Obstet Gynecol. 2016;5(10):3466-9.

16. Subedi S. Rising rate of caesarean section - a year review. J Nobel Med Coll. 2012;1(2):72-76.

17. Bergsjø P, Maltau JM. Anatomv. Bleeding in the last part of pregnancy. In Maltau BP, Molne JM, Nesheim K. Obstetrics and Gynecology. First circulation. $2^{\text {nd }}$ ed. Gyldendal Norwegian publishing house. 2010.

18. Malabary OT, Balayla J. The effect of pelvic size on cesarean delivery. J Pediatr Adolecent Gynecol. 2012;25(3):190-4.

19. Kiserud T. Chapter 10 Fetal growth and growth. In Bergsjø, P. Maltau, J.M. Molne, K. Nesheim, B.I.

20. Obstetrics and Gynecology. Gyldendal Norwegian publishing house. Second ed. first circulation 2010.

21. Unnikrishnan B, Rakshith Prasad B, Aishwarya Amarnath NK, Rekha T, Prasanna PM et al. Trends and indications for caesarean section in a tertiary care obstetric hospital in Coastal South India. Emergency. 2010;1137:64-7.

22. Hannah M, Hannah W. Caesarean section or vaginal birth for breech presentation at term. BMJ. 1996;312:1433-4.

Cite this article as: Sharma R, Dogra P. Indications and rate of caesarean delivery at tertiary care hospital: a retrospective study. Int J Reprod Contracept Obstet Gynecol 2017;6:4367-71. 